\title{
Acoustic Emission Studies on Weld Bead Defects in Nuclear Grade SS 316L Materials
}

\author{
Ranganayakulu S. V.1, Shiva Raju J.1, Kuchedludu A. ${ }^{1}$, Ramesh Kumar B.2 \\ ${ }^{1}$ Center for Non Destructive Evaluation, Gurunanak Institutions Technical Campus, Hyderabad, India \\ ${ }^{2}$ Institute for Plasma Research [IPR], Bhatt, Gujarat State, India \\ Email: nayakulu@rediffmail.com
}

Received 2 July 2014; revised 23 July 2014; accepted 21 August 2014

Copyright (C) 2014 by authors and Scientific Research Publishing Inc.

This work is licensed under the Creative Commons Attribution International License (CC BY).

http://creativecommons.org/licenses/by/4.0/

c) (i) Open Access

\begin{abstract}
This paper contributes about the behaviour of Acoustic Emission (AE) signatures of implanted weld defects of SS 316L materials. Lack of penetration and lack of side fusion defects were implanted in weld bead region of the materials. Tungsten Inert Gas Welding (TIG) is adopted to weld the Stainless Steel (SS316L) nuclear grade materials. The material is fabricated with dimensions of $140 \times 16 \times 10 \mathrm{~mm}$ and AE signatures are studied under preload conditions. Mechanical Jig is fabricated to maintain constant load in concentrated weld region. When external load is applied on the weld region, the deformed specimen experiences acoustic emission signals form the weld defect region which are potential source of releasing stress energy. Liner Location Technique (LLT) is adopted for AE singal studies and the generated signal is processed by 2-channel USB-AE node and AE-WIN software. The tests are conducted on two different samples having each defect. A conventional NDT method i.e. X-ray Radiography is conducted on the samples to know the defect ranging and correlated with $\mathrm{AE}$ signatures. This study will be helpful to standardize the $\mathrm{AE}$ signals for different implanted weld defects of SS 316L materials and it is found that, the parameter "counts vs. amplitude" has given the widest distinction with respect to the type of defects.
\end{abstract}

\section{Keywords}

Acoustic Emission Signatures, X-Ray Radiography, Lack of Side Fusion, Lack of Penetration, Tungsten Inert Gas Welding (TIG)

\section{Introduction}

Acoustic Emission is a powerful tool which is useful for the study of structural health monitoring of materials. Acoustic Emission (AE) is the study and practical use of elastic waves generated by a material subjected to an external stress [1]. The phenomenon was recognized by early miners who exited a mine when the rocks or sup- 
porting timbers started groaning. Tin cry, the sound produced when a tin bar is bent, was known soon after the production of metallic tin. Allen Green and a group at Aero Jet Corporation started using AE in the testing of Saturn Rocket Propellant tanks. They used a form of triangulation based on the arrival times of the acoustic pulse at several acoustic emission sensors. According to ASTM, Acoustic Emission refers to the generation of transient elastic waves during the rapid release of energy [2] from localized sources within a material. Other sources of Acoustic Emission are melting, phase transformation, thermal stresses cool down cracking and stress build up.

The basic idea in source location is to cover a surface with a network of sensors. If one can determine the arrival times of an emission signal at several sensors, then, knowing the acoustic velocity [3], it is possible to triangulate back to the location of the source of that emission. Most acoustic emission mechanisms involve a permanent change in the micro structure [4] of the material. Once a micro fracture occurs, it will not happen again unless there is some sort of healing mechanism. The ratio of the load value, when emission starts on subsequent loadings, to the maximum load value reached on the previous loading, known as the Felicity ratio, indicates possible damage induced by the previous loading. Many NDT tests of FRP structures apply the test load in a series of steps, returning to zero between each step. The appearance of Felicity ratios much less than 1.0 is a good indication that significant damage occurred in previous loadings.

\section{Experimental Setup of Mechanical JIG}

The samples were subjected to radiographic examinations before conducting of AE test. The defect location and magnitude were well established by these conventional methods. It is necessary to subject these samples to external loading in order to make the defects active and generate [Figure 1] Acoustic Emission (AE) signals. The generated AE is monitored with the help of two transducers in "Linear Localization" mode for locating the defects [5].

The samples were tested using the Linear Localization method. In order to make the defects active, an external force needs to be applied to the specimens. Samples were tested in a Mechanical Jig [Figure 2] specifically designed for this purpose. This special jig was designed for ease of loading and to keep the unwanted external noise to the minimum. This Jig has provision for the placement of the samples on an anvil at the lower side and in the centre. This anvil has two vertical supports with rounded tops on which the sample can be placed and pressed to obtain the deformations. A mandrill attached to a screw loading system can be lowered on to the anvil for pressing the samples. The samples are placed on the anvil in a flat position and the mandrill is lowered slowly by rotating the lever attached to the screw for loading the samples.

Two broad banded acoustic sensors having operating frequency range of $100 \mathrm{KHz}-1000 \mathrm{KHz}$, are placed on either side of the sample and Acoustic Emission data was collected while slowly loading the samples. Linear Location technique method was used while collecting the data. Suitable filters were put to avoid unwanted noise from various sources. AE signatures are recorded in terms of energy, count, and amplitude.

Two samples were tested from each of the weld category [Figure 3]. The specimens were bent to less than 45 degree angle between their two legs. Acoustic emission data was collected while slowly loading the specimens. copious emission activity was detected from both good and defective specimens. However, it was noticed that, the emission activity started much earlier in the defective specimens than from the good specimens. Also the activity from the defective samples was higher and some of the signals were noticed to be distinctly sharper. Some signals showed higher frequencies possibly from crack formation [6] during loading/deformation. It was observed that, the embedded defects showed up extra acoustic emission activity compared to specimens from good welds. The AE data was recorded for Lack of Penetration (LOP) and Lack of Side Fusion (LSF) defective samples of SS316L. NDT evaluation was also carried out on these defect specimens and the results are being correlated with AE response of the specimens.

\subsection{Experimental Setup of AE Hardware and Software}

4-Channel Acoustic Emission test setup and AE-Win Software is procured from Physical Acoustic Corporation, USA for Acoustic Emission studies. The USB AE node is a single channel Acoustic Emission (AE) digital signal processor with full hit and time based features, including waveforms. The USB-AE node system is capable of performing any AE application [Figure 4 \& Figure 5] and is an excellent field survey tool. When a structure is subjected to an external stimulus (change in pressure, load, or temperature), localized sources trigger the release of 


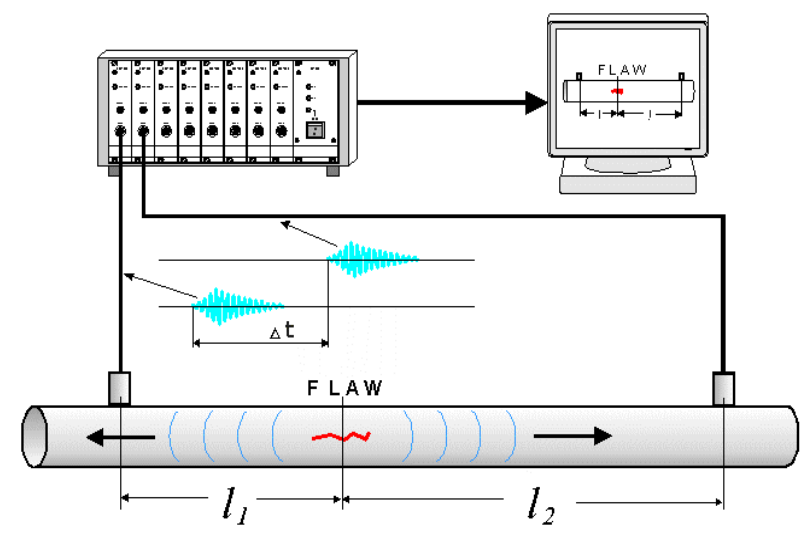

Figure 1. Set up for linera localization of AE from a flaw.

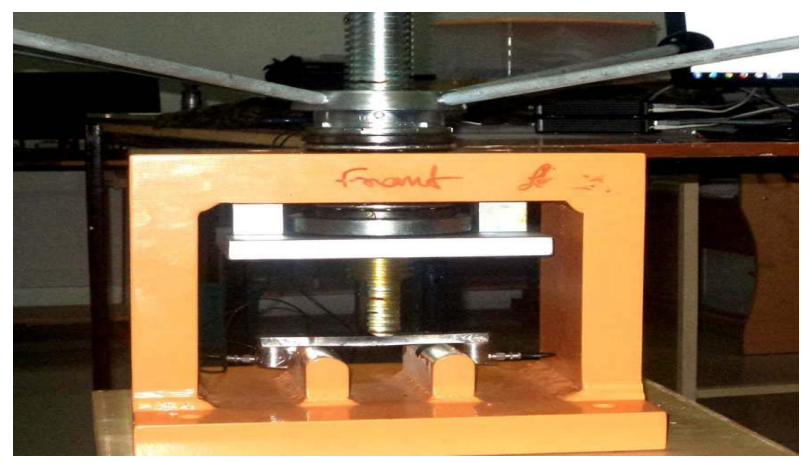

Figure 2. Sensors attached with sample in Mechanical Jig.

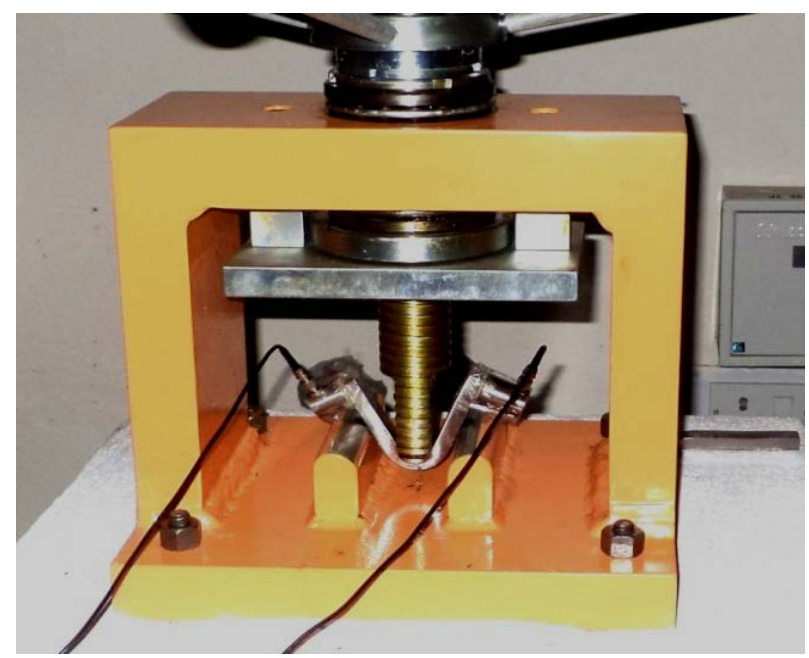

Figure 3. Bended sample under applied constant load.

energy, in the form of stress waves, which propagate [7] to the surface and are recorded by sensors. With the right equipment and setup, motions on the order of picometers $\left(10^{-12} \mathrm{~m}\right)$ can be identified. The plastic component of the strain often takes longer. Some deformation [8] is immediate but some of it is delayed [Figure 6]. Counts vs. time are plotted [9] under pre load conditions.

\subsection{Linear Location Technique}

One of the commonly used computed-source location techniques is the Linear Location technique [Figure 1] and it 


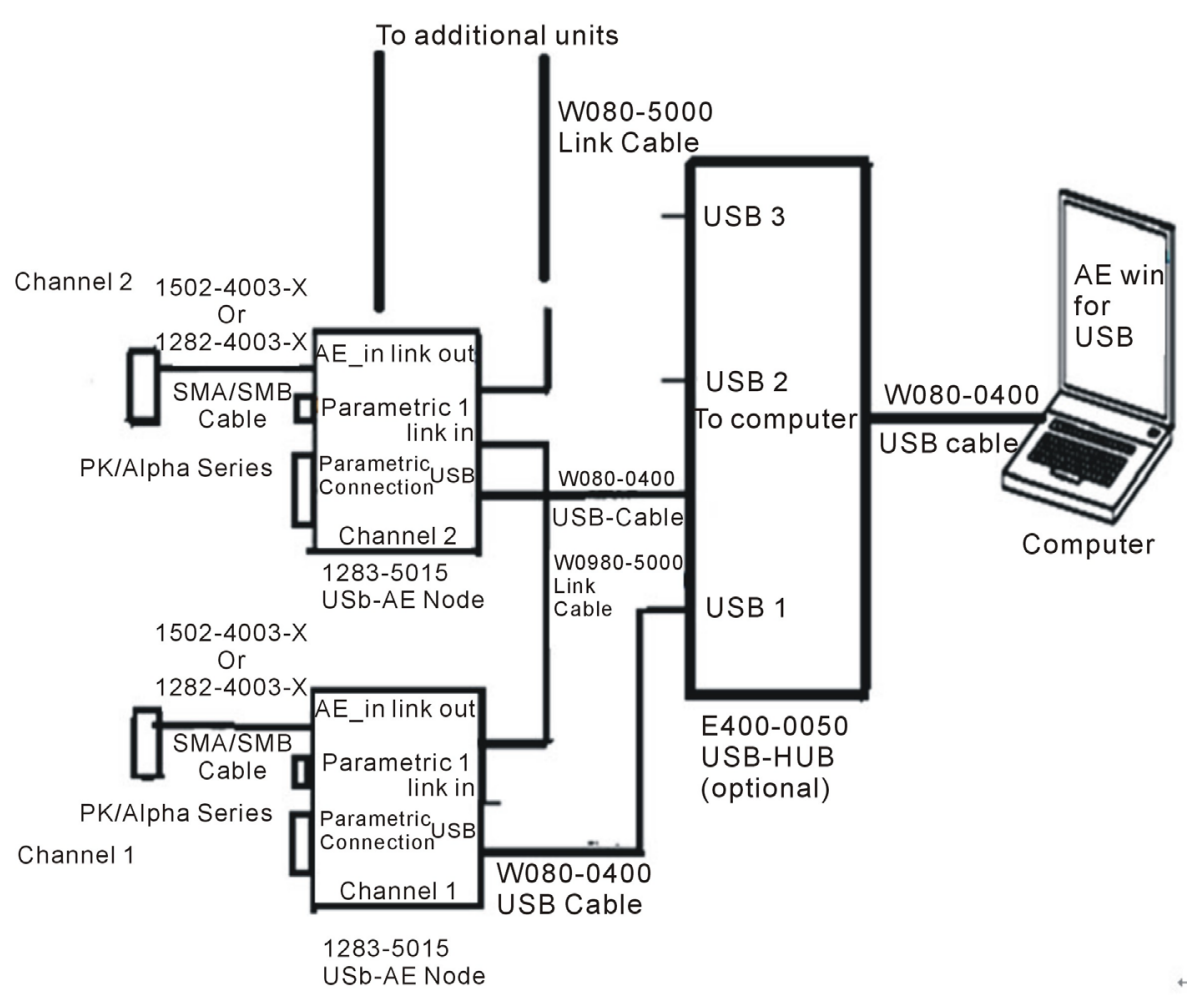

Figure 4. Typical Daisy-Chain configuration of USB-AE node and it accessories.

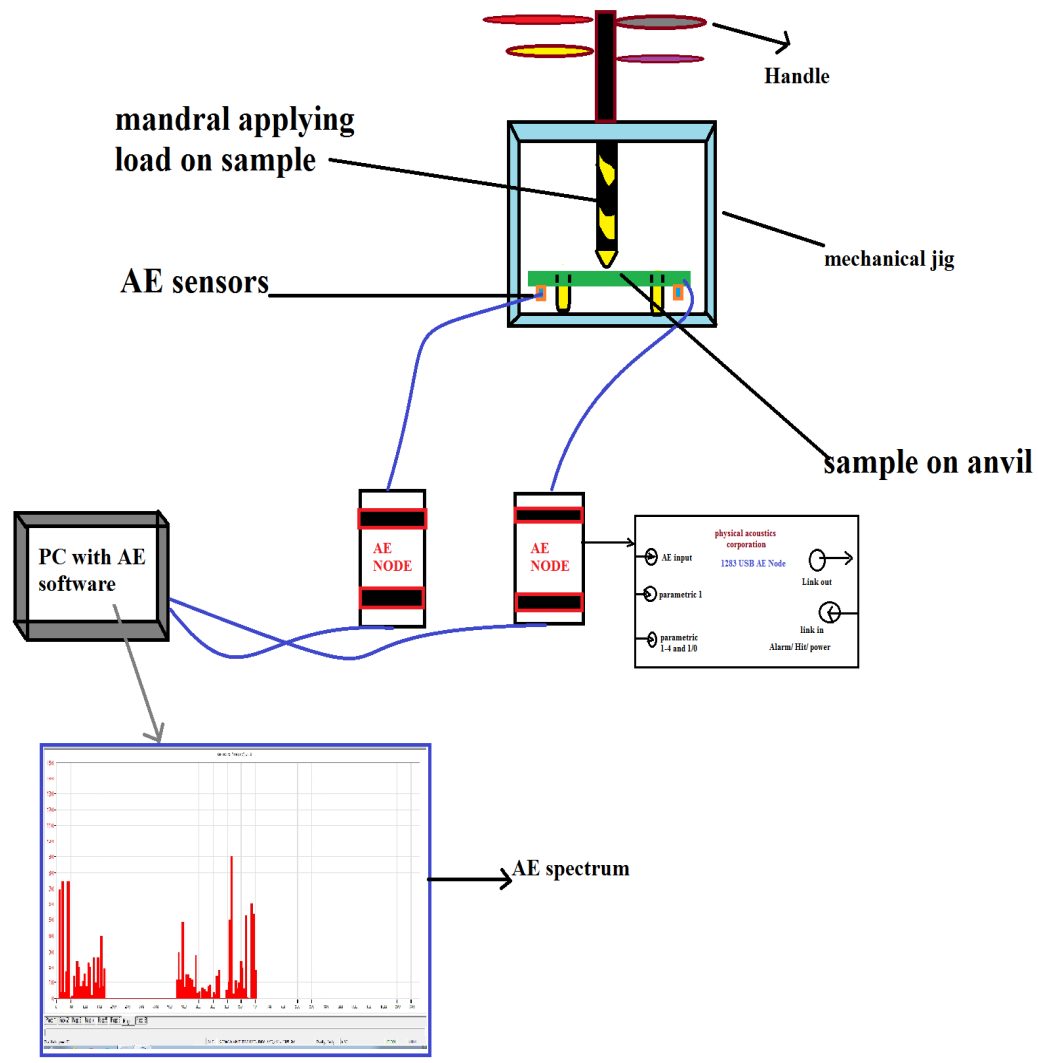

Figure 5. Schematic diagram of Acoustic Emission testing. 


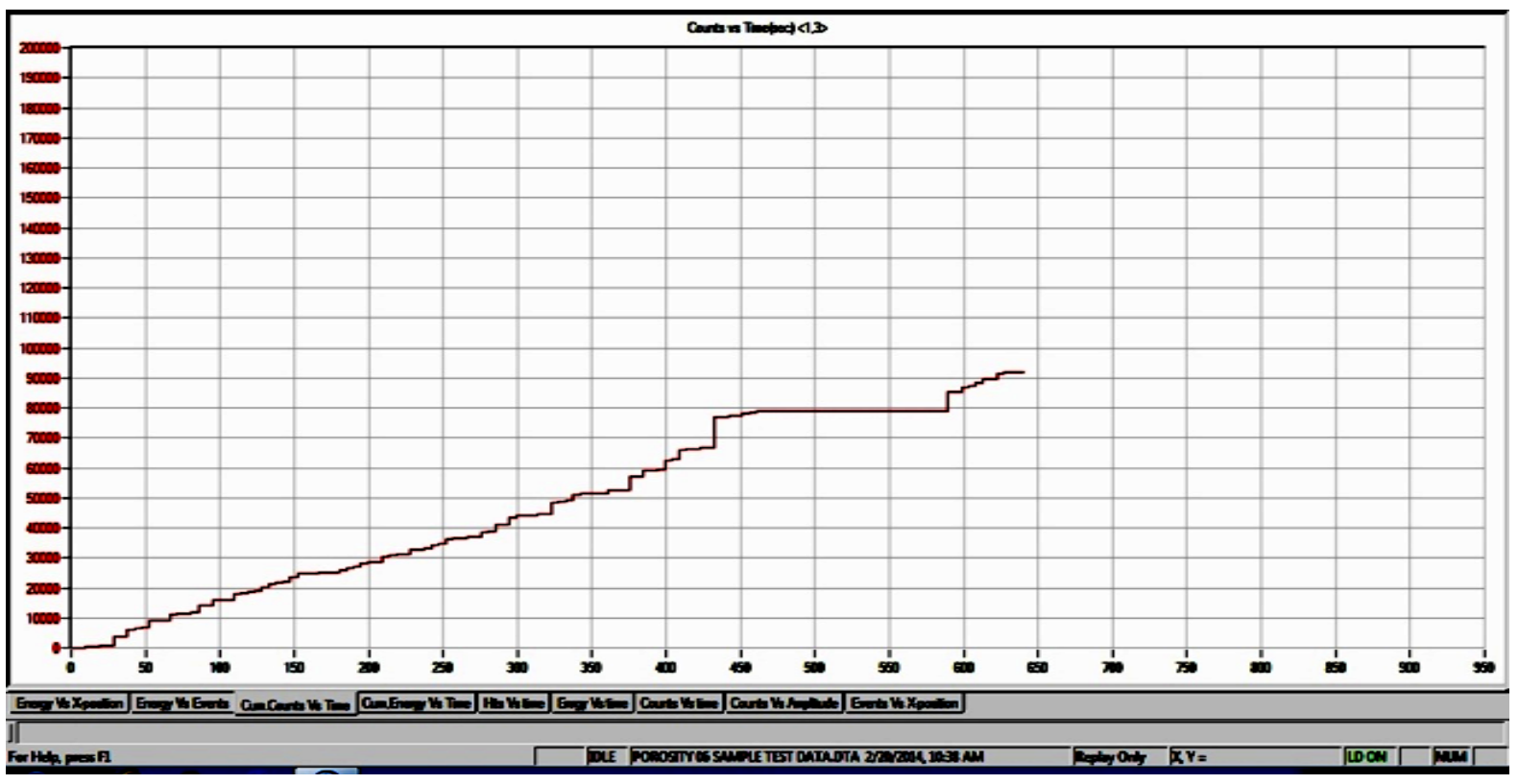

Figure 6. Acoustic Emission signals during load indicates instability.

is adopted in these studies. When the source is located at the midpoint of the weld region of the sample, the time of arrival difference [10] for the wave at the two sensors is zero. If the source is closer to one of the sensors, a difference in arrival times is measured. To calculate the distance of the source location from the midpoint, the arrival time is multiplied by the wave velocity. Whether the location lies to the right or left of the midpoint is determined by which sensor [11] first records the hit. This is a linear relationship and applies to any event sources between the sensors.

\section{Sample Preparation Details}

SS316L material is adopted for Acoustic Emission testing for experimentation because it uses in construction of nuclear reactors [12] which are having high strength. Two different types of welded specimens are taken into consideration for vast studies of signals in surrounding areas of welded region. In order to monitor the weld defects, it is necessary to create such defects in experimental welds. For this, a number of weld plates were selected with suitable dimensions and Tungsten Inert Gas (TIG) as well as manual metal arc welding was carried out as per the need.

Following are the details of the parameter adopted for welding-

Plate material: SS316 L

Plate thickness: $10 \mathrm{~mm}$

Plate length: $300 \mathrm{~mm}$

Plate width (before welding): $70 \mathrm{~mm}^{*}$

Welding method used: TIG (Welding-current 110 to 130 Amperes)

Some plates are made with good welds using proper welding methods and matching electrodes and other plates were made by deliberately introducing Lack of Penetration (LOP) and Lack of Side Fusion defects (LSF) during their welding. The plates after welding [Figure 7] had $140 \mathrm{~mm}$ length, $16 \mathrm{~mm}$ width and 10mm thickness. The different types of defected weld samples used for the studies are 1) Lack of Penetration (LOP) and 2) Lack of Side Fusion (LSF).

\section{Experimental Procedure of Radiography}

\subsection{Radiography Testing}

Radiography method is adopted as a NDT tool for identification of defects location in welded specimens. The procedure is discussed below. It involves exposing a test object to penetrating radiation so that the radiation 


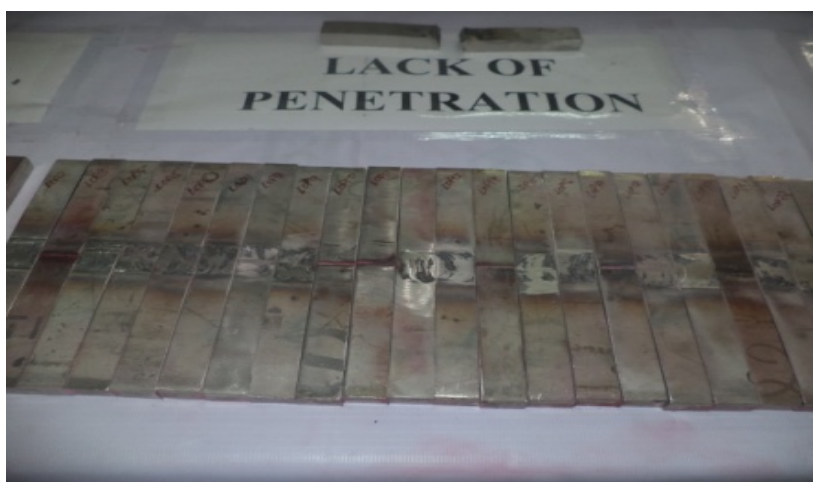

(a)

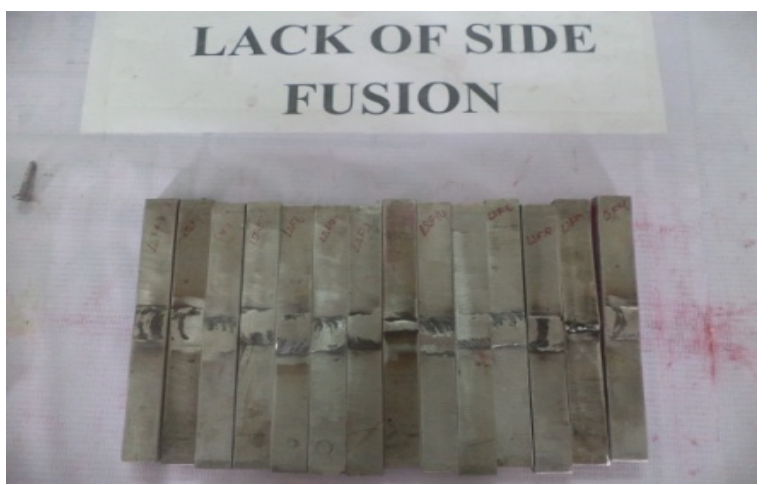

(b)

Figure 7. SS316L samples containing (a) Lack of penetration; (b) lack of side fusion for AE study under constant load.

passes through the object being inspected and a recording medium placed against the opposite side of that, object [13] [14].

\subsection{Radiographic Source}

The Radiography testing techniques shall demonstrate that, the required radiography sensitivity has been obtained. Iridium -190 is used as source in this test carried out because the recommended minimum thickness for which Radio-active isotopes when steel is $0.75 \mathrm{~m}$. The minimum recommended thickness limitation may be reduced when the radiography techniques are used to demonstrate that the required radiographic testing sensitivity has been obtained.

\subsection{Radiographic Film}

Commercially available industrial radiography film (Kodak type AA 400, FUJI 100 or AGFA D7) is used [15] in accordance with SE 1815 (ASTM) standard test method. D4 film is used for SS316L sample for inspection of defects. Radiography test is conducted to correlate itself with acoustic emission test results. Two samples consist of lack of penetration [Figure 8(a)] and lack of side fusion [Figure 8(b)] defects separately [16] taken into test cycle. Gamma ray is used as source. Wire type and Hole type Penetrameter is used [17] to check the test accuracy. The defects in the films are observed easily and $\mathrm{AE}$ test is conducted for further analysis.

\subsection{Experimental Procedure of Acoustic Emission Testing}

This experiment was carried out with cyclic loading using fixed load. It was found that, the primary emission from active crack growth occurred only at the peak load levels. In fact, the emission that occurred at the peak load levels, secondary emission and noise that occurred at lower load levels were gated out. At first when the crack was still small, not every cycle produced emission. But later as the crack approached the critical length for unstable propagation, every cycle produced emission. This fits well with the behavior of statically loaded specimens, that insignificant flaws tend to show the Kaiser Effect while structurally significant flaws tend to show the Felicity Effect. Damage assessment has been feasible because AE activities are function of parameters such as stress level in the crack Zone. AE activity can be directly related to fracture mechanics parameters which can be further related to crack growth rate and fatigue failure. Locating the source of significant acoustic emissions is often the main goal of an inspection. Although the magnitude of the damage may be unknown after AE analysis, follow up testing at source locations can provide these answers. Continuous emission [18] during deformation indicates that, weld region get fractured and open to the surface. Multi channels [19] are used to test large structures and to evaluate the emissions from the location and measurement of emission rates. An analysis can be done either in real time [20] (if the prevention of structural failure is the test objective) or in post-test analysis

\section{Results and Discussions}

Testing of two samples of Lack of Penetration and Lack of Side Fusion defects are taken for Acoustic Emission 


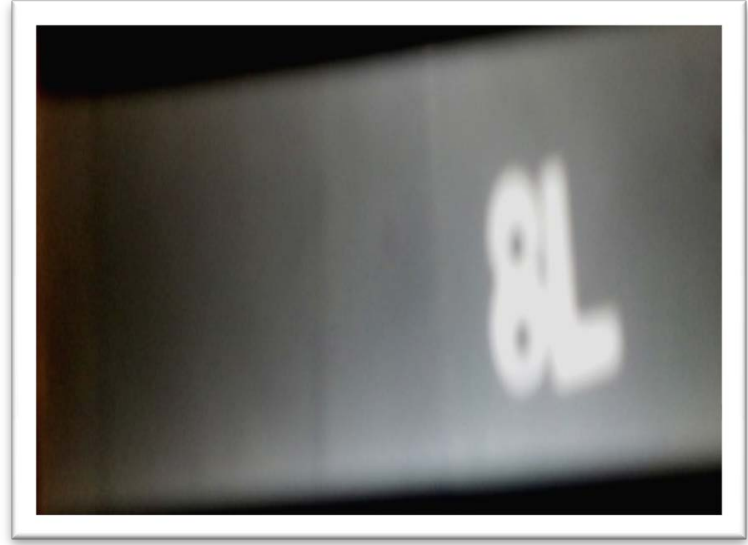

(a)

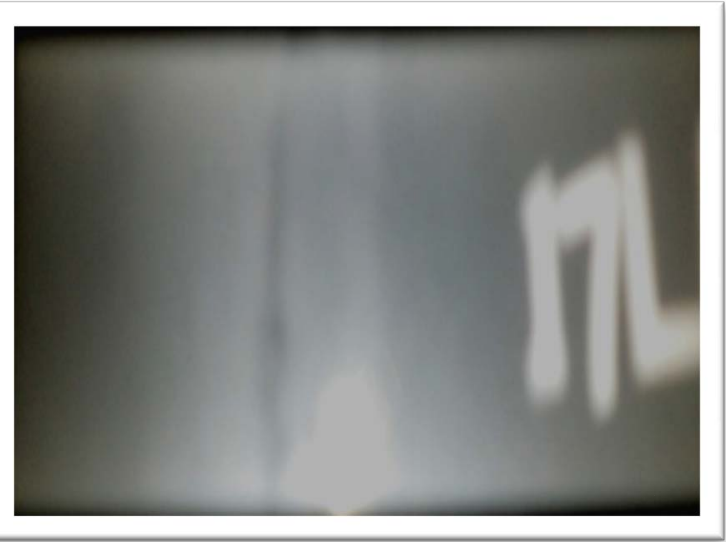

(b)

Figure 8. Radiographic film shows (a) Lack of penetration and (b) Lack of side fusion weld defects.

Studies. Linear Localization technique was used for obtaining the data. While the samples are being loaded, the events were recorded with respective to the position of transducers placed on either end of the samples. Initially, we have attempted to get clear acoustic emission signals by getting higher signal to noise ratios with good results and then shifted to the monitoring of different parameters. The first data monitored was the "Events vs. the Xposition”. Apart from this, the data was monitored in different configurations. A graph of the hits, events, counts or absolute energy vs. the load or time is essential. The graph of the cumulative hits, etc. over the graph of the rate of hits, etc. is preferred. Because, it is visually easier to differentiate a cumulative graph than to integrate a rate graph. The classic parameter vs. time graph has been used almost from the start of AE testing. A located events count is sensitive to emission [21] from actual flaws but may miss regions where only one or two sensors are activated. Counts or absolute energy per event will give the most information about the state of flaw growth but can become confusing when there are multiple flaws. Located events count is sensitive to emission from actual flaws [22] but may miss regions where only one or two sensors are activated. Changes in the slope of the cumulative graph [23] indicate changes in the acoustic emission rate. A steady rate in the absence of external noise indicates controlled flaw growth, while an increasing rate indicates uncontrolled flaw growth. When the slope of the curve appears to increase toward an exponential, or shows a distinct knee, structural failure is usually approaching.

Following are the details of the various modes in which data was obtained, compiled and analyzed.

\section{Observations Made from the Data Analysis}

\subsection{Energy vs. X-Position}

It is observed that, all the samples except one recorded a good number of events coming from the centre position [Figure 9] of the sample. This must be an aberration of the experiment rather than a characteristic feature of the defect. Events from lack of penetration are high but the events formed from lack of side [Figure 10] fusion having higher counts.

\subsection{Cumulative Counts vs. Time}

Lack of penetration and lack of side fusion defects showed very high rate of count cumulation. The lack of penetration defect showed medium rate of count cumulation [Figure 11]. It was found that lack of penetration and lack of side fusion emitted [Figure 12] plastic deformation under the load.

\subsection{Cumulative Energy vs. Time}

It was found that, more variation in cumulative energy with respect to time for Lack of Penetration [Figure 13] and Lack of Side Fusion defects. Lack of penetration showed continuous cumulative emission. In the case of lack of side fusion defect, the time for deformation is very low [Figure 14]. It indicates that, high energy is emitted due to the formation of new surface. 


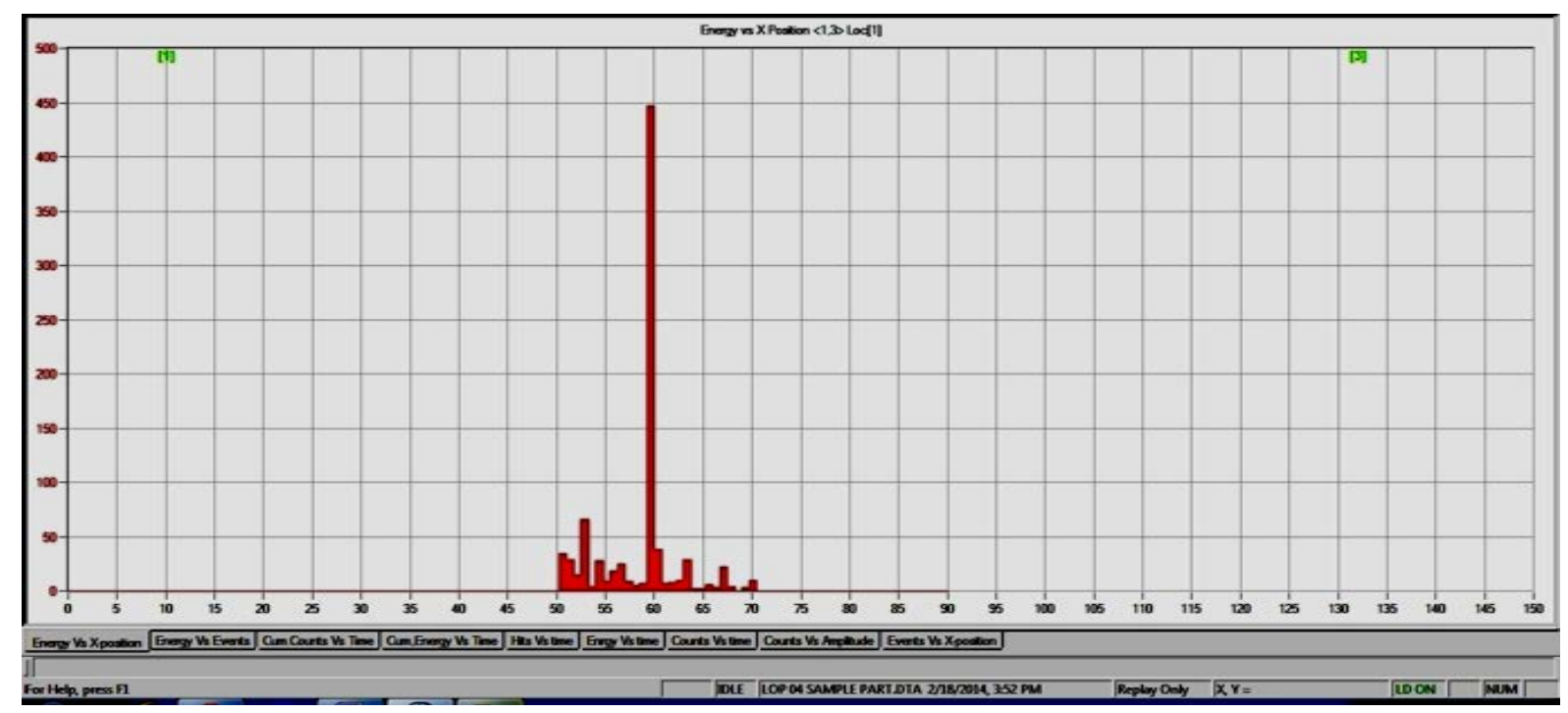

Figure 9. Energy vs. X-position for Lack of penetration defect of SS316L.

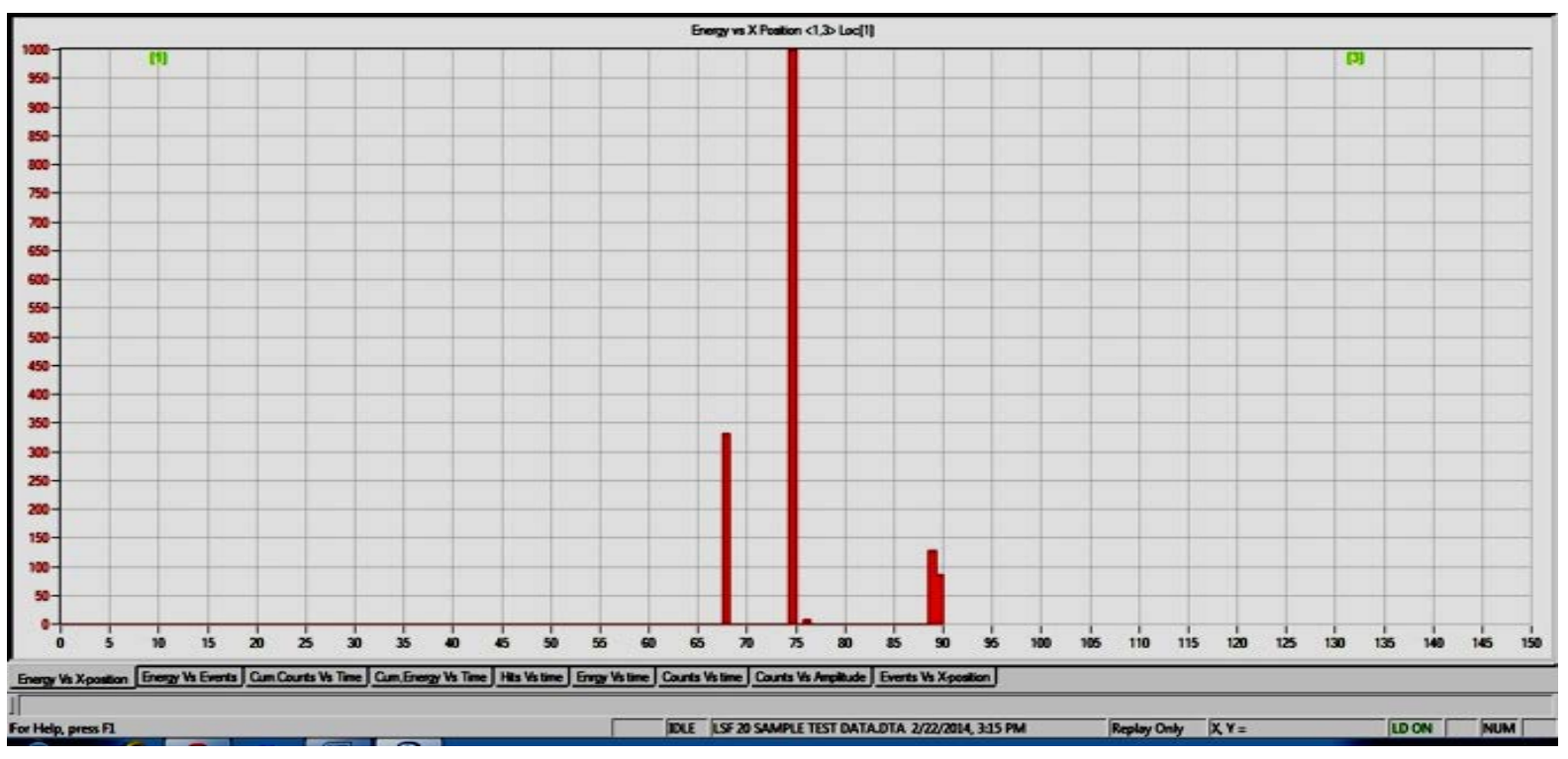

Figure 10. Energy vs. X-position for Lack of side fusion defect of SS316L.

\subsection{Hits vs. Time}

Lack of penetration recorded the highest hits than lack of side fusion defect. After observing the complete deformation, a high emission [Figure 15] is seen in lack of penetration. Owing to lack of side fusion the highest hits is emitted [Figure 16] during deformation, when new surface is formed.

\subsection{Energy vs. Time}

It was found that, the defects like lack of penetration emitted higher energy [Figure 17] than lack of side fusion. This is due to incomplete penetration or welding. The crack initiates and grows in very short time compared to side fusion [Figure 18] so it produces highest energy in that order with respect to time.

\subsection{Counts vs. Time}

It was found that, samples having lack of side fusion showed highest number of counts with respect to time. The lack of 


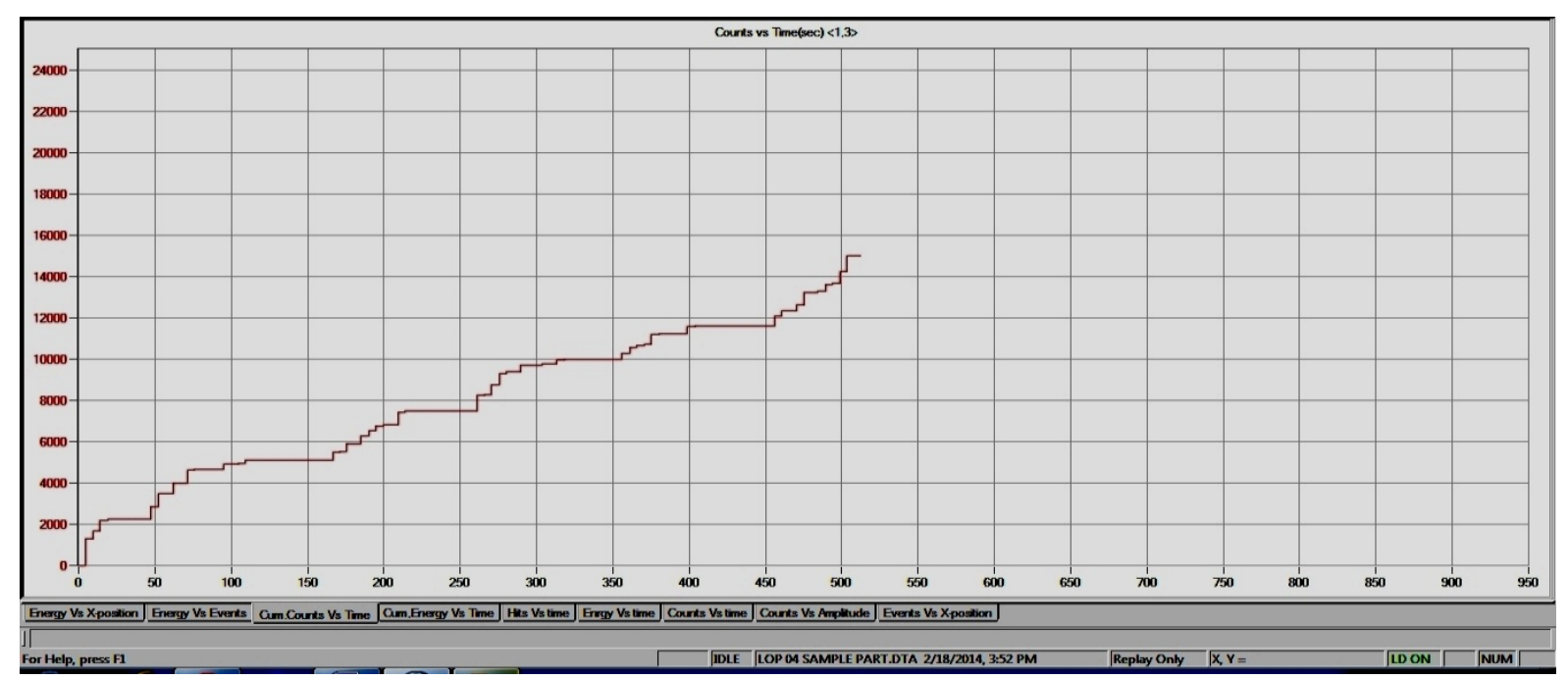

Figure 11. Cumulative Counts vs. Time for Lack of penetration defect of SS316L.

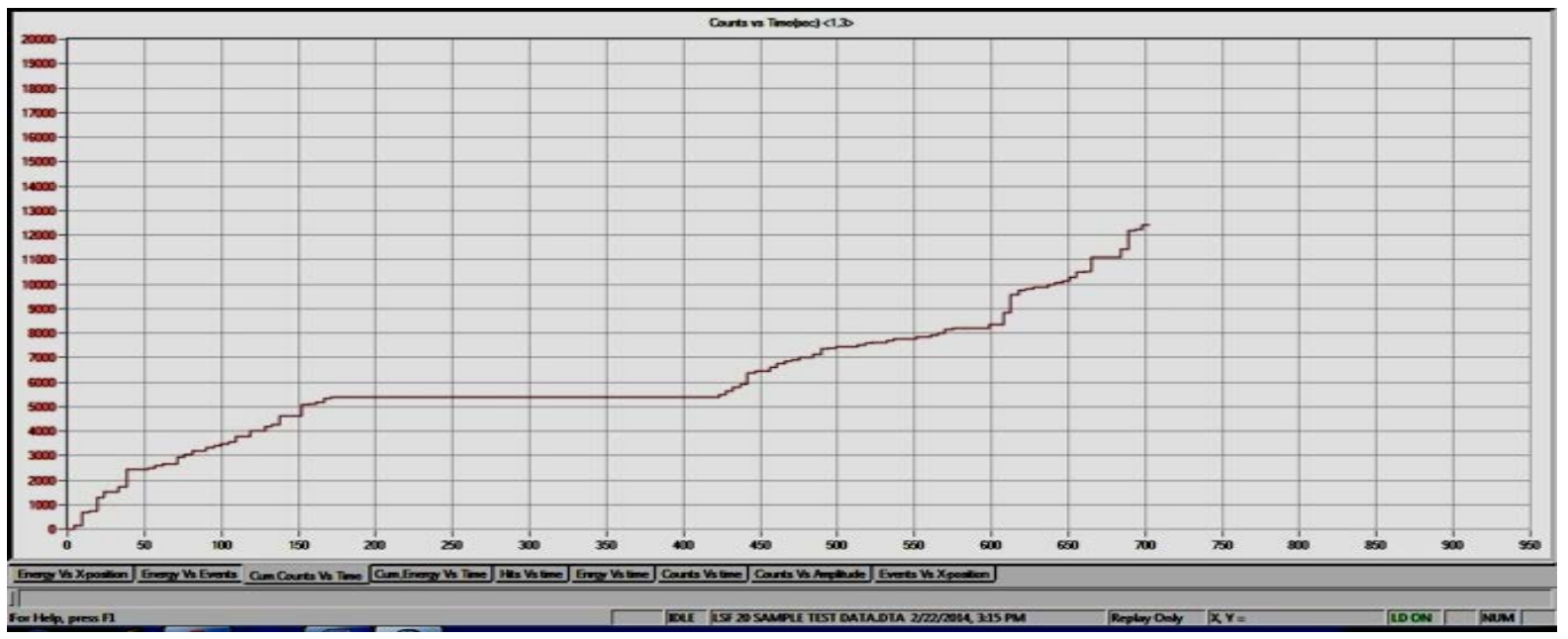

Figure 12. Cumulative Counts vs. Time for Lack of side fusion defect of SS316L.

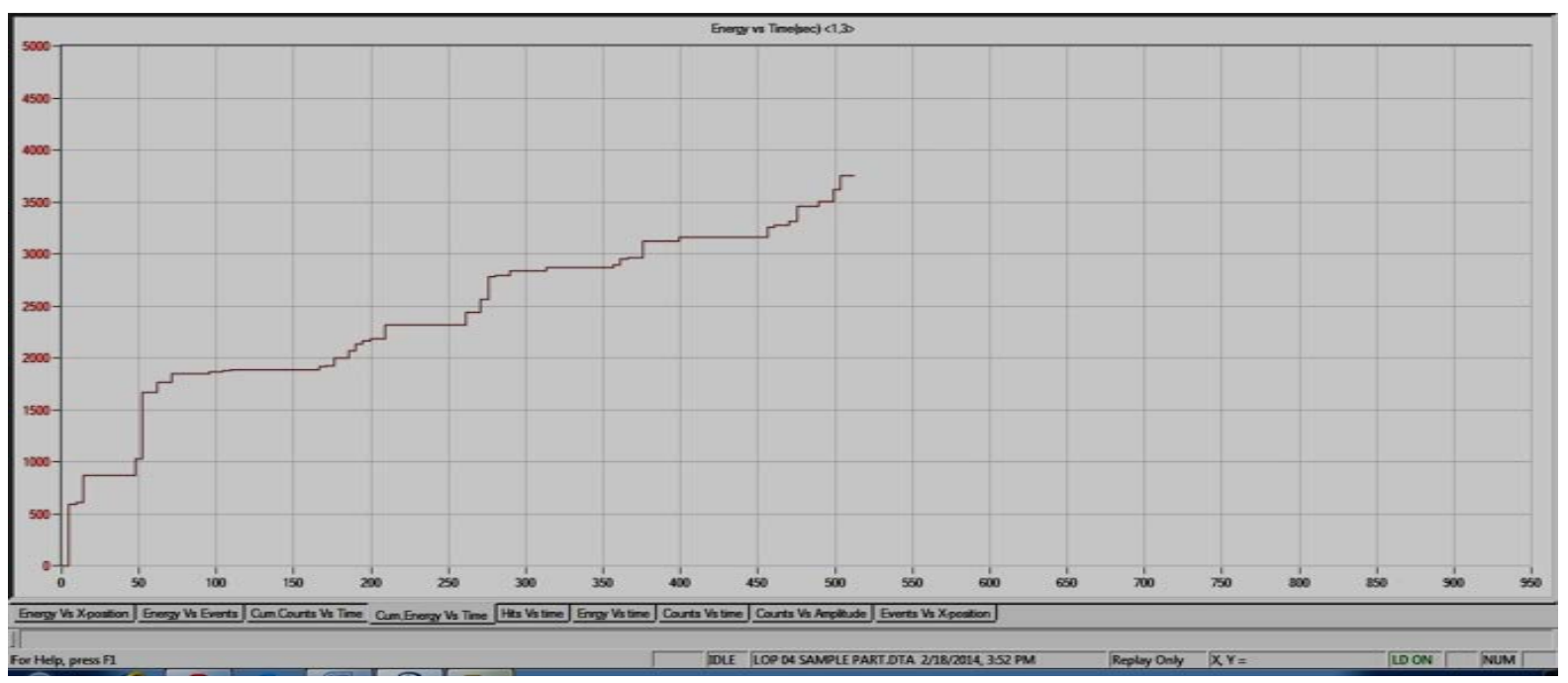

Figure 13. Cumulative Energy vs. Time for Lack of penetration defect of SS316L. 


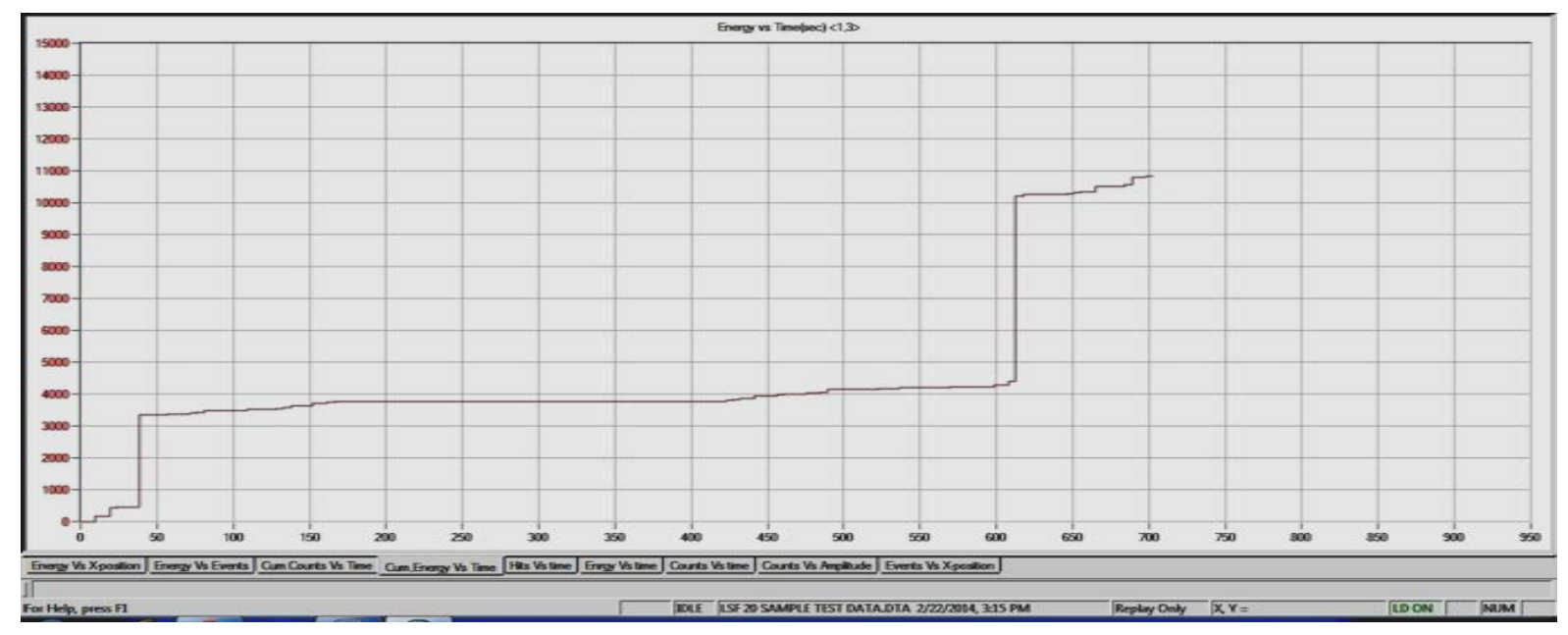

Figure 14. Cumulative Energy vs. Time for Lack of side fusion defect of SS316L.
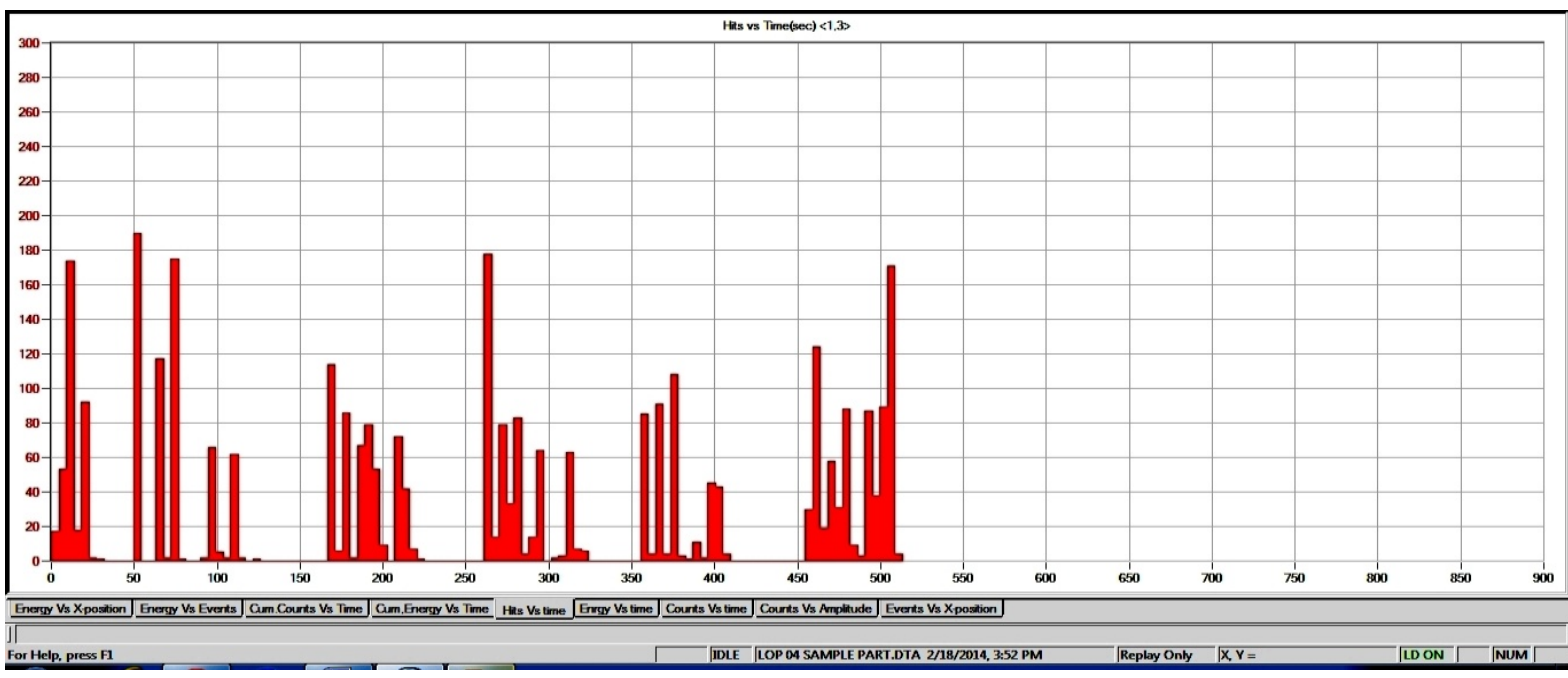

Figure 15. Hits vs. Time for Lack of penetration defect of SS316L.

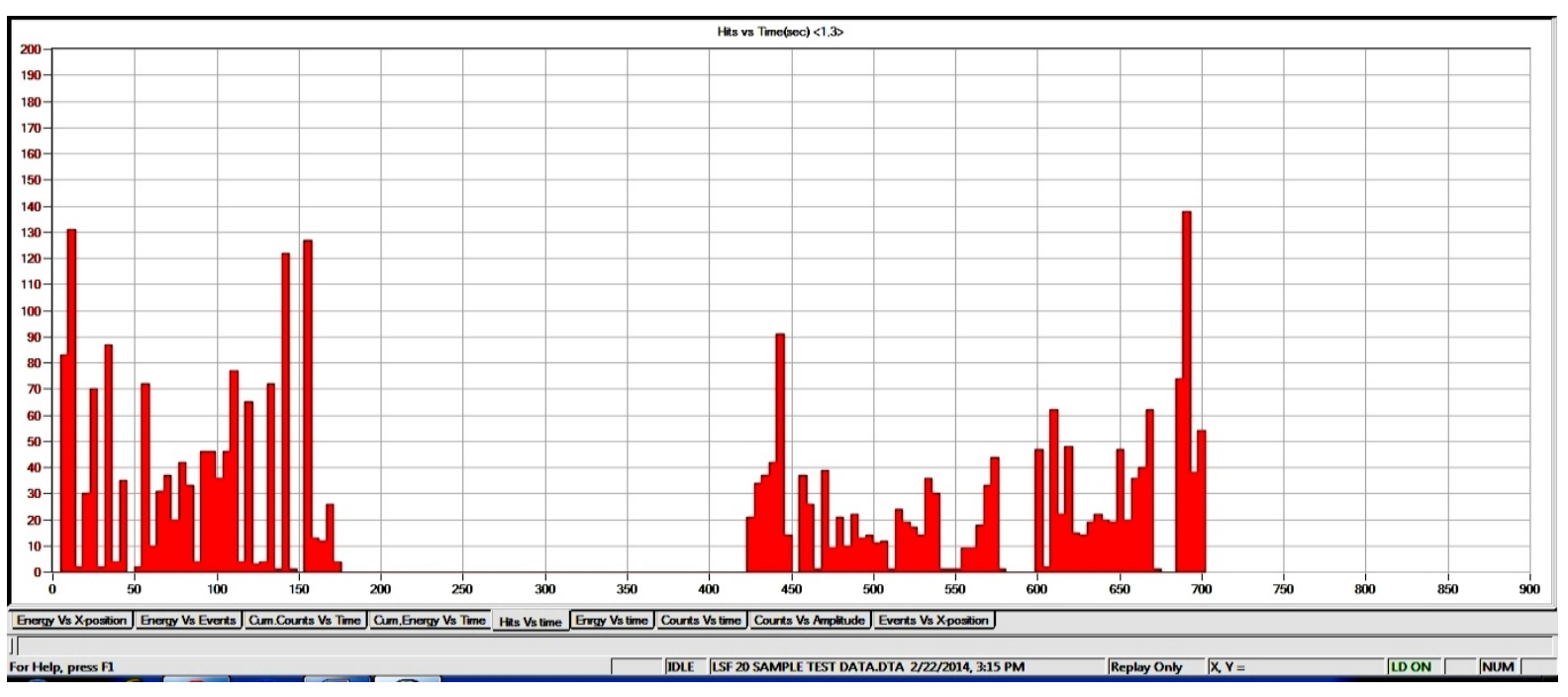

Figure 16. Hits vs. Time for Lack of side fusion defect of SS316L. 


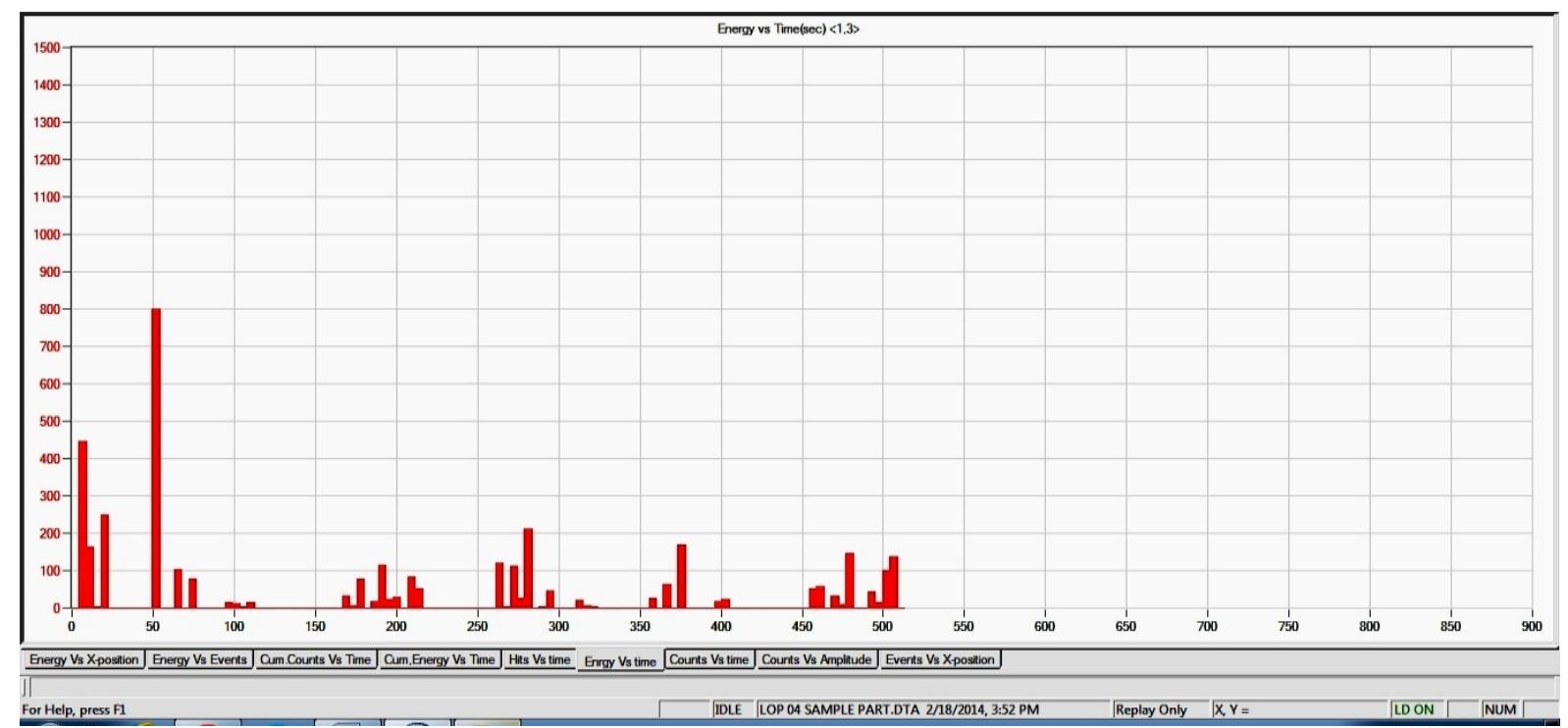

Figure 17. Energy vs. Time for Lack of penetration defect of SS316L.
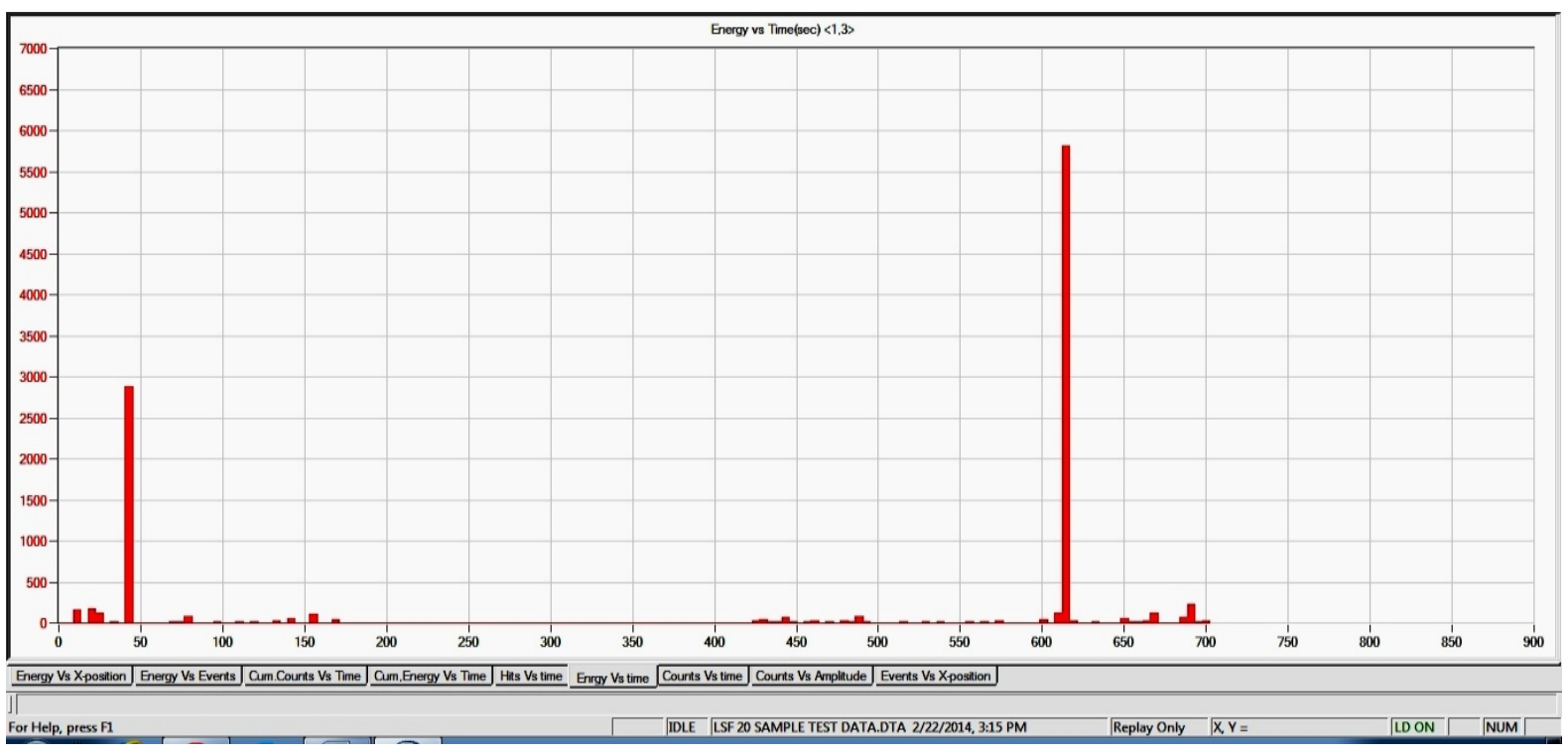

Figure 18. Energy vs. Time for Lack of side fusion defect of SS316L.

penetration defect [Figure 19] showed more counts than lack of side fusion defect [Figure 20]. This is due to deformation of old and formation of new surface in short time.

\subsection{Counts vs. Amplitude}

This particular parameter showed very distinctive differences for different defects. This particular parameter is dependable for segregation and characterization of different defects [Figure 21] in conjunction with other parameters. Defects like lack of penetration and lack of side fusion [Figure 22] recorded the highest count amplitude.

\subsection{Waveforms vs. Amplitude}

Wave forms were taken for a few events having high energy from two tested samples [Figure 23]. These wave forms are plotted amplitude vs. time. It is noticed that, there are definite characteristic features in the wave forms 


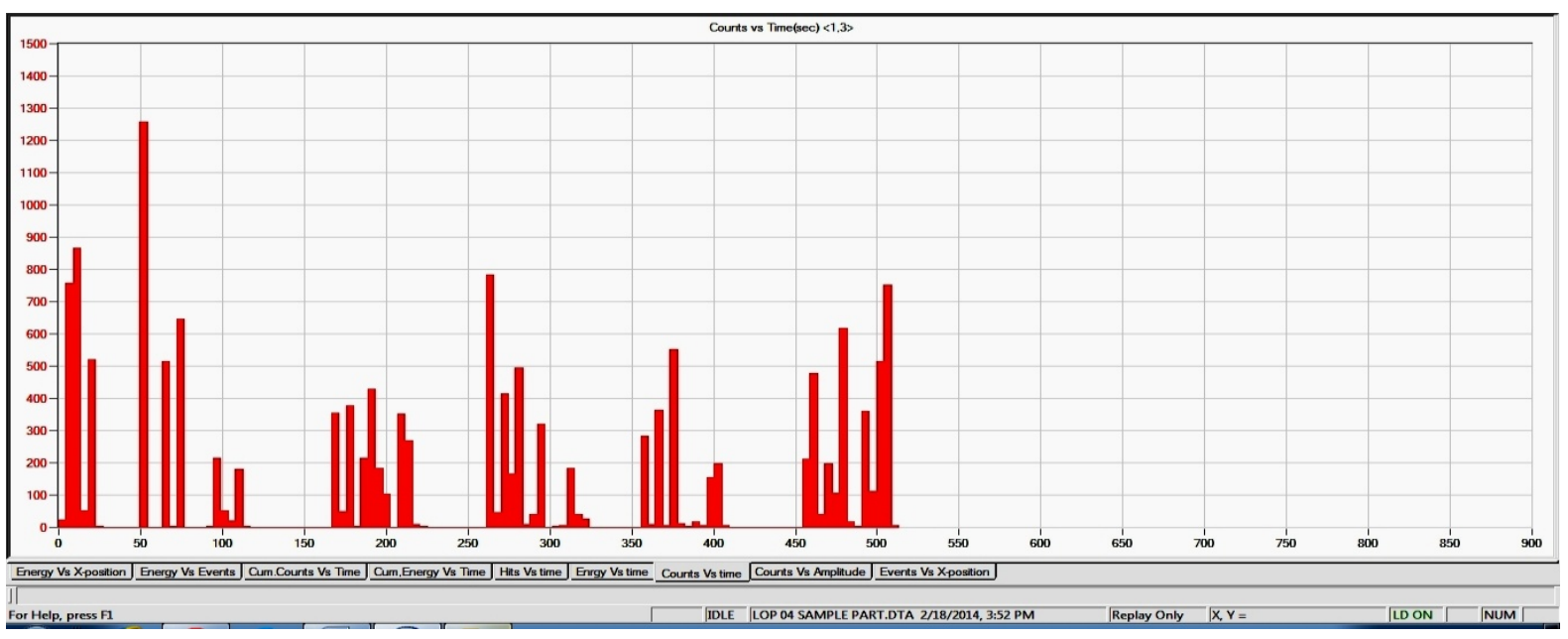

Figure 19. Counts vs. Time for Lack of penetration defect of SS316L.

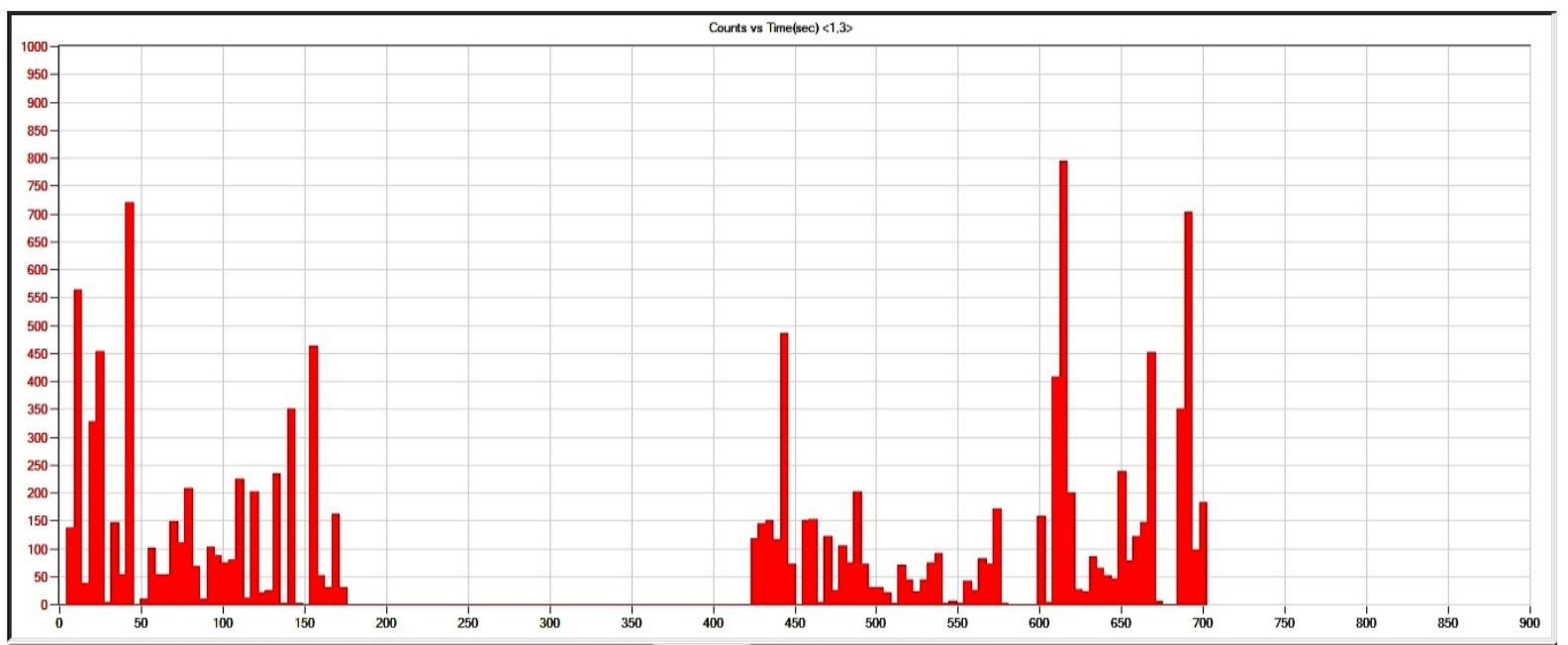

Energy Vs Xpostion Energy Vs Everts Cum Counts Vs Time Gum, Energy Vs Time Hits Vs time Ency Vs time Courts Vs time Counts Vs Anplitude Everts Vs Xposition

For Help, press F1

IIDLE LSF 20 SAMPLE TEST DATA.DTA 2/22/2014, 3:15 PM

Replay Only $X, Y=$

$[$ LD ON $\square$ NUM

Figure 20. Counts vs. Time for Lack of side fusion defect of SS316L.

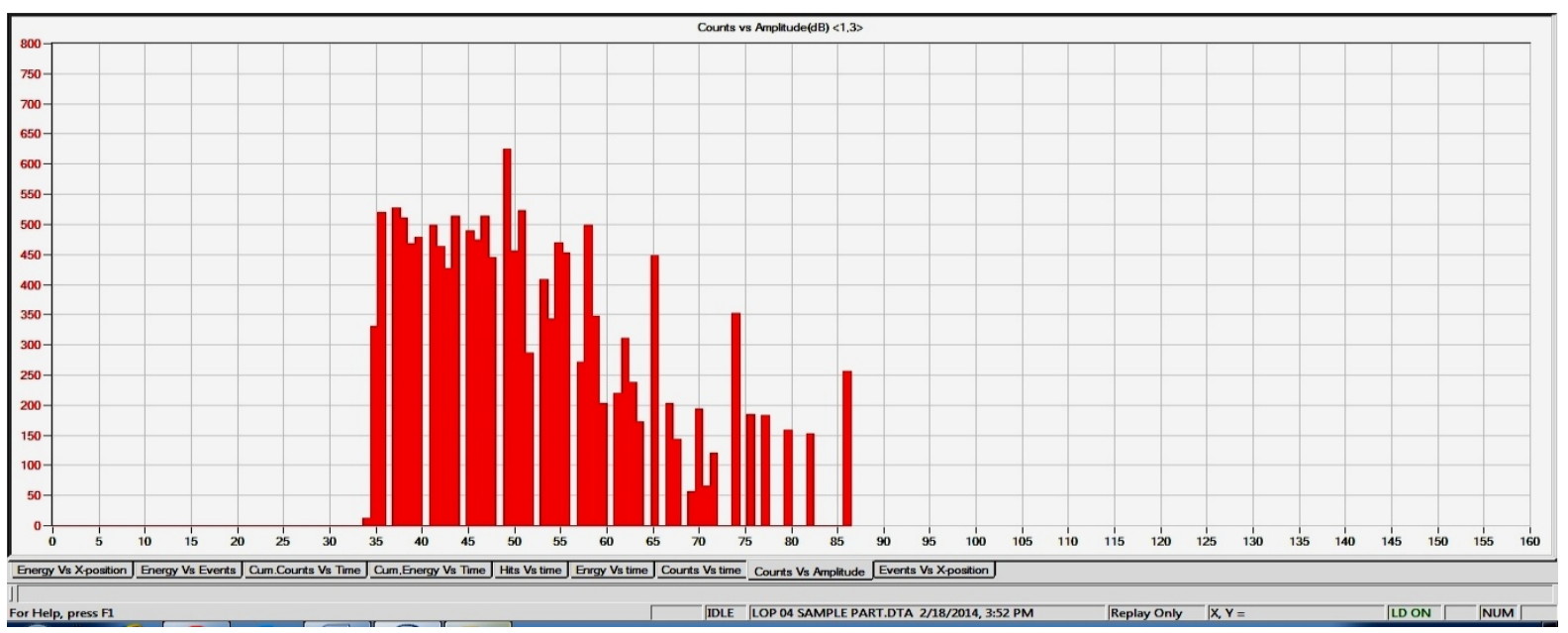

Figure 21. Counts vs. Amplitude for Lack of penetration defect of SS316L. 


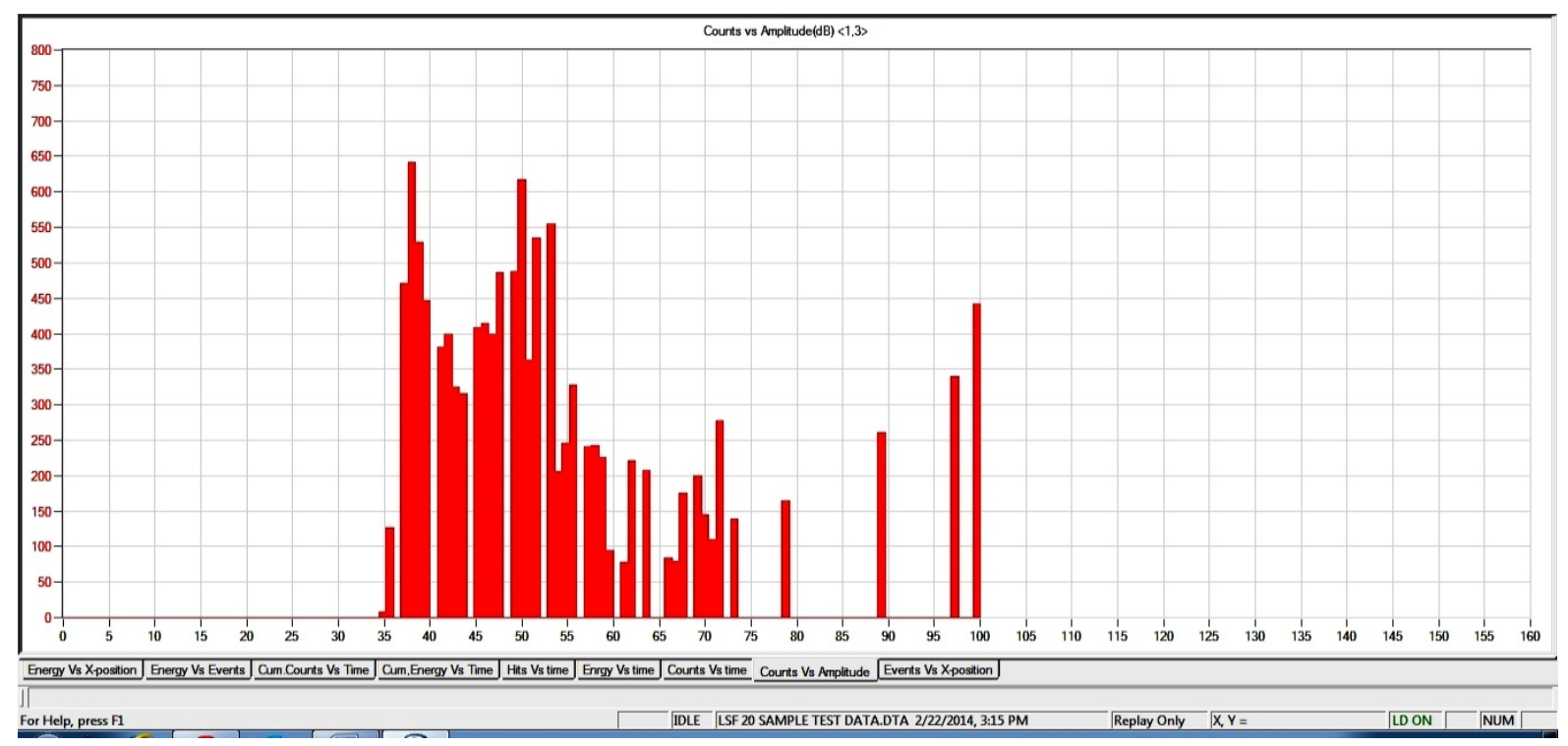

Figure 22. Counts vs. Amplitude for Lack of side fusion defect of SS316L.

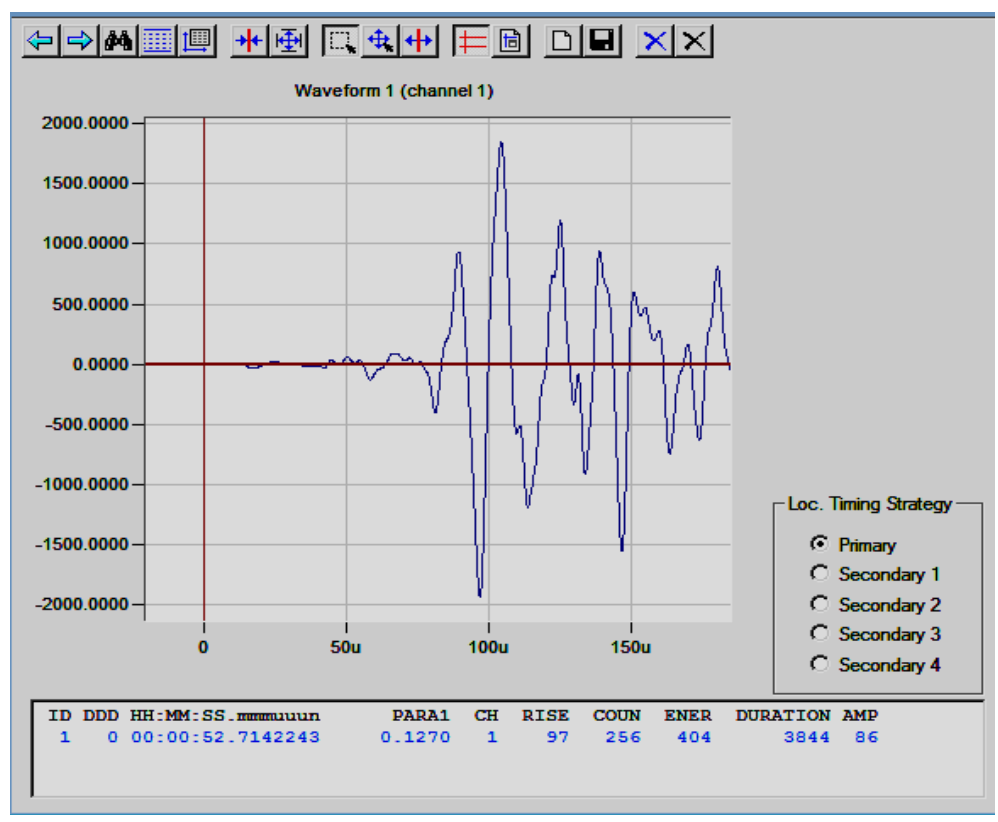

Figure 23. Amplitude vs. Time for Lack of penetration defect of SS316L.

from different defects. The defect is having higher counts showed higher energy [Figure 24] like lack of side fusion.

\subsection{Frequencies vs. Amplitude}

In the amplitude vs. frequency graphs, LOP defect has higher frequency [Figure 25] with higher amplitude content than LSF [Figure 26].

\section{Conclusion}

Data analysis was carried out for various parameters obtained from testing of two defects of samples. Comparison of various $\mathrm{AE}$ parameters showed that, there is a definite pattern with respect to the type of weld defects. It is 


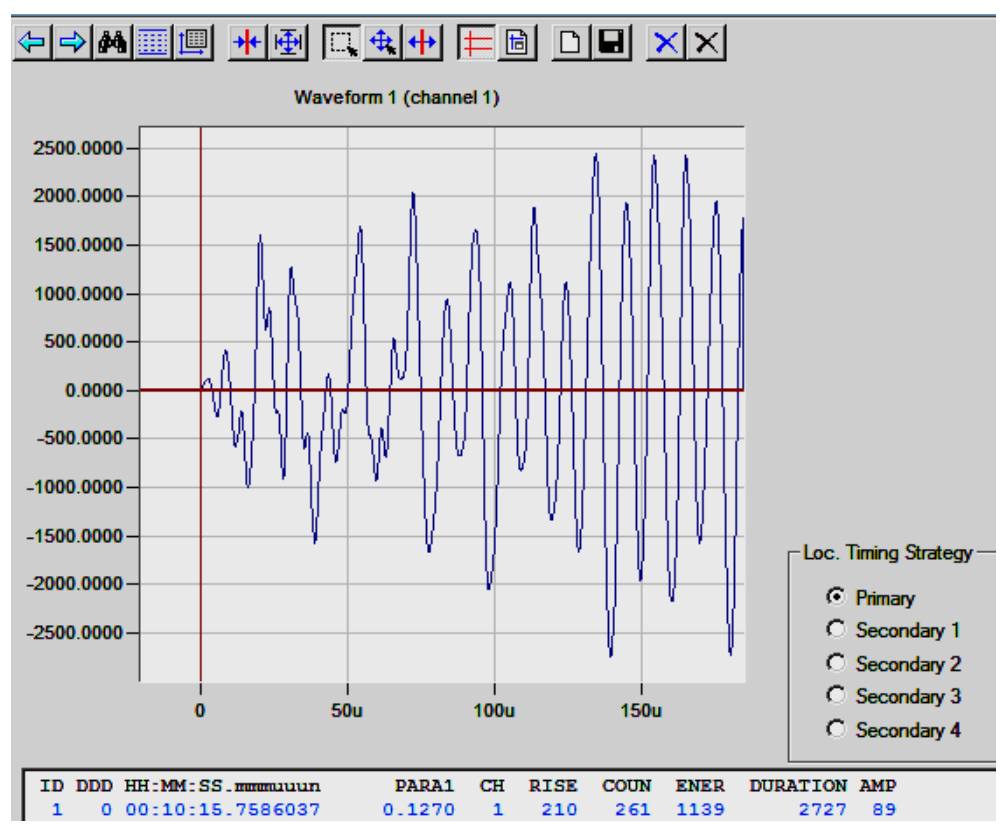

Figure 24. Amplitude vs. Time for Lack of side fusion defect of SS316L.

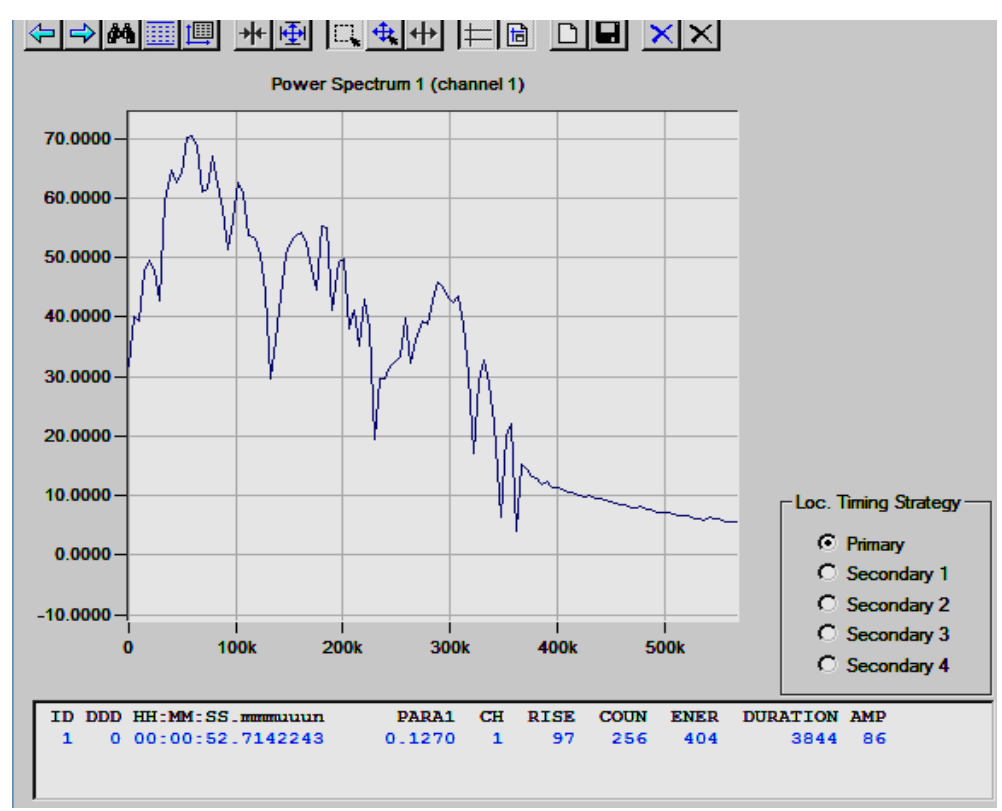

Figure 25. Frequency Spectrum for Lack of penetration defect of SS316L.

observed that, the parameter "counts vs. amplitude" has given the widest distinction with respect to the type of defects. The defects like, lack of penetration have highest expression when compared to lack of side fusion defect in any of the AE parameters monitored. This lack of penetration (LOP) showed the highest counts vs. amplitude and also the highest amplitude with respect to frequency of the events. Energy raised during deformation was observed high with lack of side fusion defect.

\section{Acknowledgements}

Authors are grateful to the Board of Research in Fusion Science \& Technology of Institute for Plasma Research academic research project programme for grant in aid (Project no: NFP-MATF12-01) to pursue the project. 


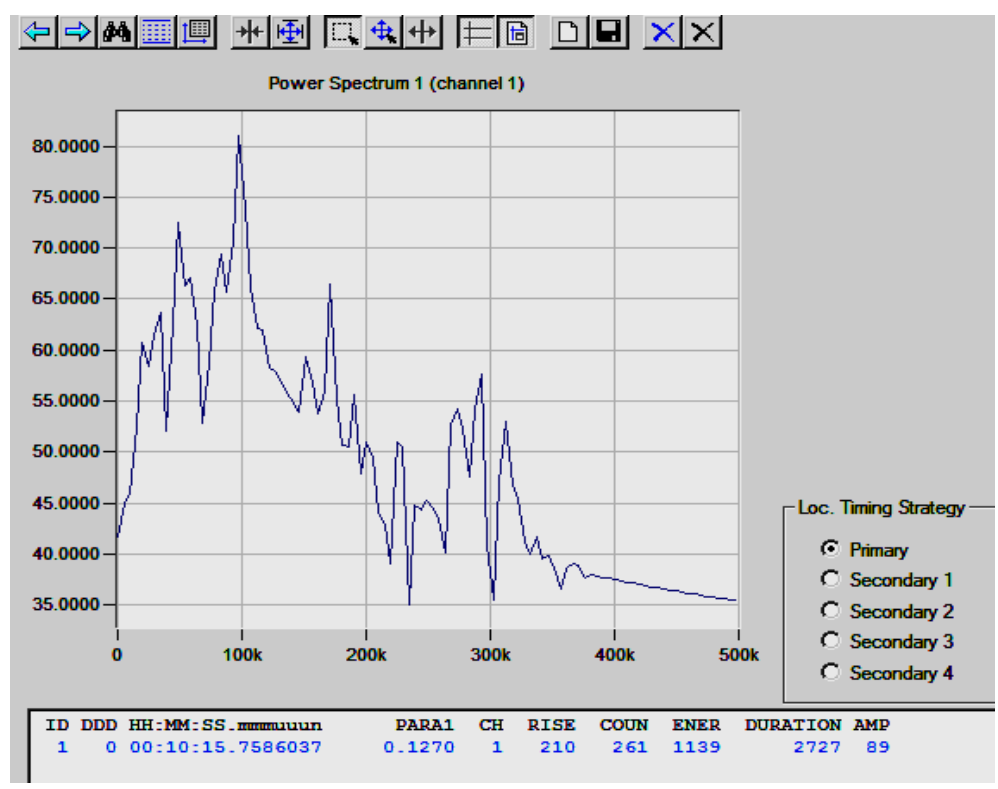

Figure 26. Frequency Spectrum for Lack of side fusion defect of SS316L

Gratefully acknowledgements due to "Dr. H. S. Saini, Managing Director and Sardar G. S. Kohli, Vice Chairman, Guru Nanak Institutions, Ibrahimpatnam for cooperation and encouragement.

\section{References}

[1] Acoustic Emission Testing. Nondestructive Testing Handbook. 3rd edition, Vol. 6. American Society for Non-destructive Testing, 2005.

[2] McLaskey, G.C. and Glaser, S.D. (2012) Acoustic Emission Sensor Calibration for Absolute Source Measurements. Journal of Nondestructive Evaluation, 31, 157-168. http://dx.doi.org/10.1007/s10921-012-0131-2

[3] Raj, B. and Jayakumar, T. (1990) Acoustic Emission during Tensile Deformation and Fracture of Austenitic Alloys. Acoustic Emission Current Practices and Future Directions-ASTM STP 1077, 218-241.

[4] Camerini, C.S., Rebello, J.M.A. and Soares, S.D. (1992) Relationship between Acoustic Emission and CTOD Testing for a Structural Steel. NDT \& E International, 25, 127-133.

[5] Dia, S., Monnier, T., Godin, N. and Zhang F. (2012) Primary Calibration of Acoustic Emission Sensors by the Method of Reciprocity, Theoretical and Experimental Considerations. 30th European Conference on Acoustic Emission Testing \& 7th International Conference on Acoustic Emission University of Granada, 12-15 September 2012.

[6] Brunner, A.J., Tannert, T. and Vallée, T. (2010) Waveform Analysis of Acoustic Emission Monitoring of Tensile Tests on Welded Wood-Joints. Journal of Acoustic EMISSION, 28, 59-67.

[7] Keprt, J. and Benes, P. (2007) Determination of Uncertainty in Calibration of Acoustic Emission Sensors. 4th International Conference on NDT, Chania, 11-14 October 2007.

[8] Armentrut D.L. and Carpenter S.H. (1997) An Investigation of Luders Band Deformation and the Associated Acoustic Emission Al-4.5\% Mg Alloys. Journal of Acoustic Emission, 15, 43-51,

[9] Carpenter, S.H., Ono, K. and Armentrout, D. (2006) Acoustic Emission of Sensitized 304 Stainless Steel with Simultaneous Hydrogen Charging. Journal of Acoustic Emission, 24, 119-126.

[10] Vahaviolos, S.J. (1998) ASTM STP 1353 Acoustic Emission Standards and Technology Update. ASTM, Florida, 76, 77.

[11] Keeprt, J. and Benes, P. (2008) A Comparison of AE Sensor Calibration Methods. Journal of Acoustic Emission, 26, 60-70.

[12] Romrell, D.M. (1973) Acoustic Emission Weld Monitoring of Nuclear Components. Journal of Welding Research Supplement, 81-92.

[13] ASTM E94-04 (2010) Standard Guide for Radiographic Examination.

[14] ASTM E390-11, Standard Reference Radiographs for Steel Fusion Welds. 
[15] ASTM E1815-08 (2013) Standard Test Method for Classification of Film Systems for Industrial Radiography.

[16] ASTM E1032-12, Standard Test Method for Radiographic Examination of Weldments.

[17] ASTM E592-99 (2009) e11, Standard Guide to Obtainable ASTM Equivalent Penetrameter Sensitivity for Radiography of Steel Plates 1/4 to 2 in. (6 to $51 \mathrm{~mm}$ ) Thick with X Rays and 1 to 6 in. (25 to $152 \mathrm{~mm}$ ) Thick with Cobalt-60.

[18] Raasekhar, P., Bhat, M.R., Murthy, C.R.L., Phanira, C., Jayakumar, T. and Baldev Raj (2006) Discrimination of Nuclear grade Steel Samples Subjected to Different Heat Treatment Procedures Based on Acoustic Emission (AE) Data Profiling a Crack Initiation. Proceedings of National Seminar on Non-Destructive Evaluation, Hyderabad, 7-9 December 2006.

[19] Aljets, D., Chong, A., Wilcox, S. and Holford, K. (2010) Acoustic Emission Source Location in Plate-Like Structures Using a Closely Arranged Triangular Sensor Array. Journal of Acoustic Emission, 28, 85-98.

[20] George Varkey Strategic Electronics Group (2003) On-Line Processing of Acoustic Emission Signals. Awareness Seminar on Digital Signal Processing (ASDSP-2003), Paper 7, 1-12.

[21] Manthei, G. (2010) Characterization of Acoustic Emission Sensors. Proceedings of European Conference on Acoustic Emission Testing, Venna, 8-10 September 2010.

[22] Ennaceur, C., Lakshimi, A., Hervve, C., Ediouni, M. and Cherfaui, M. (2004) Acoustic Emission Technique and Potential Difference Method for Detecting the Different Stages of Crack Propagation in Carbon and Stainless Steels. Journal of Acoustic Emission, 22, 71-76.

[23] Mukhopadhyay, C.K., Ray, K.K., Jayakumar, T. and Raj, B. (2000) Acoustic Emission Stress Intensity Factor Relations for Tensile Deformation of Notched Specimens of AISI Type 304 Stainless Steel. Materials Science and Engineering: A, 293, 137-145. 
Scientific Research Publishing (SCIRP) is one of the largest Open Access journal publishers. It is currently publishing more than 200 open access, online, peer-reviewed journals covering a wide range of academic disciplines. SCIRP serves the worldwide academic communities and contributes to the progress and application of science with its publication.

Other selected journals from SCIRP are listed as below. Submit your manuscript to us via either submit@scirp.org or Online Submission Portal.
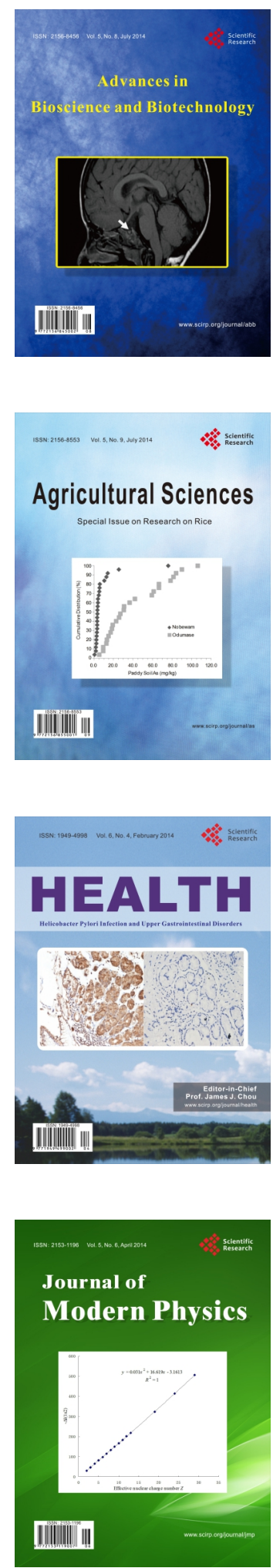
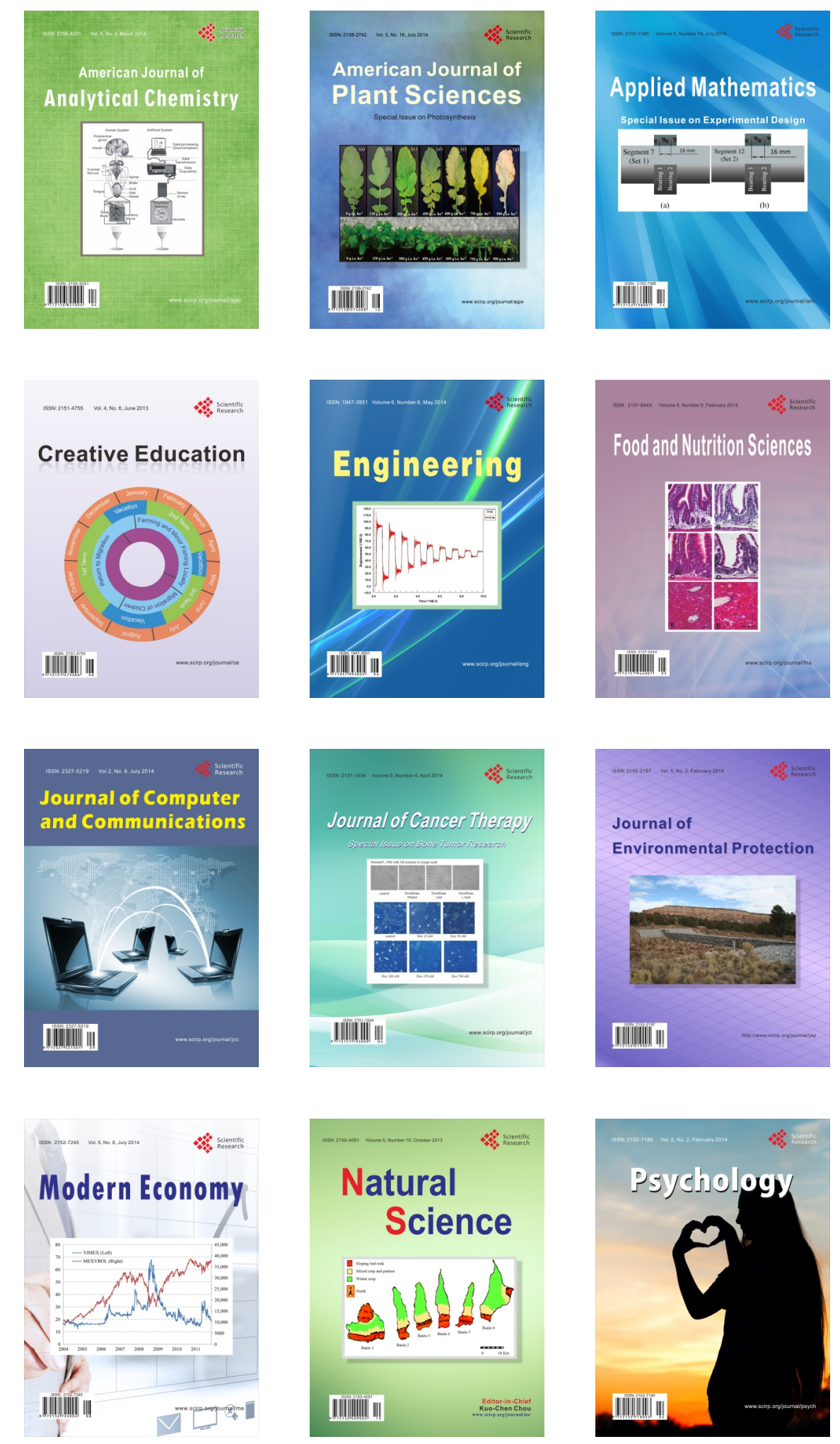